\title{
Neurophysiological studies on workers exposed to lead
}

\author{
J JEYARATNAM, ${ }^{1}$ G DEVATHASAN,${ }^{2}$ C N ONG, ' W O PHOON, ${ }^{1}$ AND P K WONG
}

From the Departments of Social Medicine and Public Health ${ }^{1}$ and Medicine, ${ }^{2}$ Faculty of Medicine, National University of Singapore, Singapore 0316, Republic of Singapore

ABSTRACT Nerve conduction and somatosensory evoked potential studies were undertaken on 46 workers exposed to a combination of organic and inorganic lead. In addition electroencephalograms were carried out on 20 of the workers; the results were compared with those obtained for workers not exposed to lead. The workers exposed to lead had a mean blood lead concentration of $2.35 \mu \mathrm{mol} / \mathrm{l}(48.7 \mu \mathrm{g} / 100 \mathrm{ml})$, whereas the concentration for workers not exposed to lead was $0.76 \mu \mathrm{mol} / 1(15.8 \mu \mathrm{g} / 100 \mathrm{ml})$. The mean maximum motor conduction velocities of the median and the posterior tibial nerves were significantly lower in the workers exposed to lead than in the controls. Similarly, the distal latency for these two nerves was significantly prolonged for the workers exposed to lead. No significant differences for the two groups of workers were seen in the nerve conduction and distal latency measurements of the median (sensory) and the sural nerves. The EEG studies of the 20 workers exposed to lead showed no abnormalities. The somatosensory evoked potential of the median (sensory) and posterior tibial nerves were significantly prolonged when measured at the negative and positive deflections. The results suggest that, in addition to nerve conduction velocities, somatosensory evoked potential and distal latency are suitable measurements to detect subclinical neurological damage among workers exposed to lead. As these changes were seen at blood lead concentrations of $2.35 \mu \mathrm{mol} / 1(48.7 \mu \mathrm{g} / 100 \mathrm{ml})$ there may be a need for more stringent monitoring of workers exposed to lead.

In most countries occupational exposure to lead is adequately controlled to prevent the occurrence of overt lead poisoning. The question arises, however, as to whether the lack of clinical evidence of lead poisoning is necessarily an indication that the worker is completely free from the ill effects of lead. Recent studies have shown evidence of subclinical effects of lead at blood concentrations below those at which clinical symptoms of lead poisoning are usually manifest. The usual tests used to show these subclinical effects relate to neurophysiological studies on peripheral nerves. The results of these studies have been variable; many workers have shown an alteration in the peripheral nerve conduction velocity in the absence of neurological symptoms. ${ }^{1-5}$ On the other hand, Illis et al were unable to show neurophysiological changes in the absence of clinical evidence of lead poisoning. ${ }^{6}$ Ashby considers that the reason for this variation in observation is

Received 18 April 1984 Accepted 14 May 1984 due to methodological differences. ${ }^{4}$ More specifically, Hernberg considers the lack of standardisation of the methods used for estimating blood lead concentrations to be an important contributory factor to the variability in observations, ${ }^{5}$ and he suggests that laboratories undertaking these studies take stringent measures to minimise variability in the estimation of blood lead concentrations.

The present study was undertaken in the light of these inconsistencies and also to examine the value of previously untested neurophysiological parameters. Furthermore, the previous investigations were undertaken on workers exposed to inorganic lead, whereas the present study was carried out on workers exposed to both inorganic and organic lead.

\section{Materials and methods}

The study was undertaken in a company in Singapore that manufactures lead based stabilisers exported to various parts of the world. Basically, the process entails the melting of lead ingots, with subsequent oxidation and chemical reaction to produce 
tribasic lead sulphate and lead stearate which are marketed as stabilisers for the manufacturer of polyvinylchloride.

The manufacturing company has a work force with a high labour turnover but at any one time about 30 people are employed on the process. This study was undertaken during 1983 , and all the workers were examined weekly at the departments of social medicine and public health and of medicine; this was part of the routine monitoring programme for workers exposed to lead. A history, physical examination, analysis of blood and urine, electroencephalogram (EEG), and neurophysiological tests were undertaken. The EEG was performed on only the first 20 workers and was discontinued thereafter. The occupational history indicated no previous occupational exposure to lead or other neurotoxic substances and none of the workers suffered from diabetes mellitus or from the chronic effects of excessive alcohol consumption.

\section{Blood lead estimation}

For blood lead analysis, $2 \mathrm{ml}$ of heparinised blood were collected by venepuncture. Precautions were taken during the collection of samples to prevent contamination so far as possible by using plastic disposable syringes, and the blood was collected in lead free polystyrene tubes for analysis.

Lead analysis was carried out using a modified Delves method utilising a Perkin-Elmer Model 107 Spectrophotometer with Delves accessories. Laboratory analysis was carried out at the department of social medicine and public health in Singapore, which is a collaborating laboratory with the National External Quality Assessment Scheme (NEQAS) in Birmingham, United Kingdom. The precision of blood lead analysis in our laboratory over the range of 0.24 to $3.86 \mu \mathrm{mol} / \mathrm{l}(5 \mu \mathrm{g}$ to 80 $\mu \mathrm{g} / 100 \mathrm{ml})$ is $\pm 0.072 \mu \mathrm{mol} / \mathrm{l}(1.50 \mu \mathrm{g} / 100 \mathrm{ml})$. As an additional check on the determination, duplicate blood samples were occasionally sent to the Western Infirmary, Glasgow, for comparison.

\section{Neurophysiological methods}

Nerve conduction studies and scalp somatosensory evoked potential (SSEP) studies were performed by a neurologist and his technician. Detailed methods and results for Singapore workers not exposed to lead have already been published. ${ }^{78}$ Measurements were made with a Medelec electrophysiological system (Model MS6) with two channel averaging facilities. Tracings were recorded on light sensitive paper. The room temperature was maintained constantly at $30-31^{\circ} \mathrm{C}$ and skin impedance was kept below 10 kohms for all recordings.

Maximum motor conduction velocity (MMCV) and distal motor latency of the median and posterior tibial nerves were determined. The median nerve was stimulated at the wrist $(13 \mathrm{~cm}$ from the base of the forefinger) and at the elbow. The muscle action potential of the thenar muscles were recorded with surface disc electrodes. The maximum conduction velocity and distal latency of the posterior tibial nerve were obtained by stimulation at the tip of the medial malleolus and in the popliteal fossa recording the contraction of the abductor hallucis brevis.

The median maximum sensory nerve conduction velocity (MSCV) was measured by stimulating the forefinger with ring electrodes and recording orthodromically at the wrist $(13 \mathrm{~cm}$ from the base of the forefinger). The sural MSCV was recorded by stimulating at the mid-calf $15 \mathrm{~cm}$ from the tip of the lateral malleolus and recording the antidromic volleys at the ankle, just below the lateral malleolus.

The scalp somatosensory early evoked potentials (SSEP) of the median and posterior tibial nerves were recorded, the nerves being stimulated at the wrist and medial malleolus respectively. Stimulation voltage was increased to just below motor threshold point and square pulses of $\mathbf{0 . 2}$ milliseconds were delivered at $2 \mathrm{~Hz}$. Low and high frequency filters were set at $1.6 \mathrm{~Hz}$ and $3.2 \mathrm{KHz}$ respectively. Ar average of 128 responses were taken and each result was tested for reproducibility. Each potential was recorded from the scalp using a fine Grass umipolar needle placed subcutaneously. The indifferent electrode was a surface button electrode placed at the midfrontal position; the active electrode for the median nerve was placed $7 \mathrm{~cm}$ from the midline, 2.5 $\mathrm{cm}$ behind a line connecting the vertex with the external auditory meatus. The corresponding site for the posterior tibial nerve was located $1 \mathrm{~cm}$ anterior to the $\mathrm{CZ}$ position.

The components of the median SSEP recorded were the negative deflection $\mathrm{N}_{20}$, positive peak $P_{25}$, and their amplitide difference. In the case of the posterior tibial SSEP the first prominent response is

Table 1 Mean blood lead $(\mathrm{PbB})$ values of lead workers and controls

\begin{tabular}{llll}
\hline $\begin{array}{l}\text { Category of } \\
\text { workers }\end{array}$ & $\begin{array}{l}\text { No of } \\
\text { lead } \\
\text { workers }\end{array}$ & $\begin{array}{l}\text { Mean PbB } \\
\mu \text { moll } \\
(\mu g / 100 ~ m l)\end{array}$ & $p$ \\
\hline $\begin{array}{l}\text { Singapore workers } \\
\text { not exposed to } \\
\text { lead9 }\end{array}$ & 64 & $0.76(15.8)$ & $0.13(2.7)$ \\
$\begin{array}{l}\text { All lead workers } \\
\text { studied }\end{array}$ & 46 & $2.35(48.7)$ & $0.70(14.4)<0.0001$ \\
$\begin{array}{l}\text { Lead workers with } \\
\text { EEG studies }\end{array}$ & 20 & $2.31(47.9)$ & $0.46(9.6)$ \\
\hline
\end{tabular}

\section{政}


Table 2 Neurophysiological data; lead workers compared with controls?

\begin{tabular}{|c|c|c|c|c|c|c|}
\hline \multirow[t]{2}{*}{ Neurophysiological measure } & & \multicolumn{2}{|c|}{$\begin{array}{l}\text { Lead workers present } \\
\text { study }\end{array}$} & \multicolumn{2}{|c|}{$\begin{array}{l}\text { Workers not exposed } \\
\text { to lead? }\end{array}$} & \multirow[t]{2}{*}{$p$} \\
\hline & & No & Mean & No & Mean & \\
\hline $\begin{array}{l}\text { Median (sensory) nerve (MSCV) } \\
\text { Sural nerve } \\
\text { Median (motor) nerve (MMCV) } \\
\text { Posterior tibial nerve }\end{array}$ & $\begin{array}{l}\text { Conduction velocity } \mathrm{m} / \mathrm{s} \\
\text { Conduction velocity } \mathrm{m} / \mathrm{s} \\
\text { Distal latency } \\
\text { conduction velocity } \mathrm{m} / \mathrm{s} \\
\text { Distal latency } \\
\text { conduction velocity } \mathrm{m} / \mathrm{s}\end{array}$ & $\begin{array}{l}46 \\
46 \\
46 \\
46 \\
46 \\
46\end{array}$ & $\begin{array}{r}46 \cdot 7 \\
44 \cdot 2 \\
4 \cdot 2 \\
54 \cdot 7 \\
5 \cdot 8 \\
47 \cdot 2\end{array}$ & $\begin{array}{l}96 \\
50 \\
96 \\
96 \\
82 \\
82\end{array}$ & $\begin{array}{r}45 \cdot 7 \\
44 \cdot 9 \\
3 \cdot 2 \\
61 \cdot 3 \\
5 \cdot 1 \\
49 \cdot 6\end{array}$ & $\begin{array}{l}<0.0001 \\
<0.0001 \\
<0.0001 \\
<0.025\end{array}$ \\
\hline
\end{tabular}

a positive deflection $P_{35}$ followed by a negative peak $\mathbf{N}_{40}$. The height of each patient was recorded and the latencies derived (for the leg nerve) were adjusted by simple arithmetical proportions to a standard height of $167.6 \mathrm{~cm}$.

\section{Results}

A total of 46 workers exposed to lead was studied. All the workers were subjected to the same procedures except for the 20 workers on whom the EEG was also carried out. The mean blood lead concentration of the 46 workers exposed to lead was 2.35 $\mu \mathrm{mol} / \mathrm{l}(48.7 \mu \mathrm{g} / 100 \mathrm{ml})$; the mean blood lead value for the 20 workers on whom EEGs were performed was $2.31 \mu \mathrm{mol} / \mathrm{l}(47.9 \mu \mathrm{g} / 100 \mathrm{ml})$. The blood level of workers not exposed to lead in Singapore has been estimated at $0.76 \mu \mathrm{mol} / \mathrm{l}(15.8 \mu \mathrm{g} / 100 \mathrm{ml}){ }^{9}$ a value significantly different from that of the workers exposed to lead in the present study (table 1).

The data from the neurophysiological parameters in the present study were compared with data from Singapore workers not exposed to lead' (table 2). All the data on the neurophysiological parameters were obtained from the same laboratory under similar conditions and techniques. The two sets of data were tabulated into four age groups as a $2 \times 4$ table with unequal replication within each cell, and the difference in sample means were tested using 2-way orthogonal ANOVA. No statistically significant differences were seen between the two groups when the data from the median (sensory) nerve or from the sural nerve were compared. The maximum con- duction (motor) velocity and the distal latency of the median and posterior tibial nerves were, however, significantly slower and more prolonged in the lead workers when compared with values from workers not occupationally exposed to lead (table 2).

Finally, the data from the SSEP of the median (sensory) and posterior tibial nerves from the lead workers were compared with the published values for workers not exposed to lead ${ }^{8}$ using 2 tailed tests (table 3 ). It was observed that the $\mathrm{N}_{20}$ and $\mathrm{P}_{35}$ values for the median (sensory) and posterior tibial nerves were significantly prolonged in the lead workers.

\section{Discussion}

This study was undertaken primarily to detect subclinical evidence of neurological changes in workers exposed to lead. As the workers in the study were exposed both to organic and inorganic lead, EEG studies were performed to examine the possibility of any subclinical evidence of brain dysfunction since organic lead is known to be more likely to cause encephalopathic changes. The results of the EEG examination, however, showed no abnormalities in these workers exposed to lead even though, at the time of EEG examination, they had a mean blood concentration of $2.31 \mu \mathrm{mol} / \mathrm{l}(47.9 \mu \mathrm{g} / 100 \mathrm{ml})$ (table 1), which is almost three times the mean value $(0.96 \mu \mathrm{mol} / \mathrm{l}, 15.8 \mu \mathrm{g} / 100 \mathrm{ml})$ in people not occupationally exposed to lead in Singapore..$^{9}$ The absence of abnormalities in the EEG does not necessarily exclude the possibility of subclinical brain dysfunction as it is possible that the EEG may not be

Table 3 Somatosensory evoked response of median (sensory) and posterior tibial nerves in lead workers and controls

\begin{tabular}{|c|c|c|c|c|c|c|c|}
\hline \multirow[t]{2}{*}{ Nerve } & \multicolumn{3}{|c|}{ Lead workers } & \multicolumn{3}{|c|}{ Workers not exposed to lead } & \multirow[t]{2}{*}{$p$} \\
\hline & No & Mean $(\mathrm{m} / \mathrm{s})$ & $S D$ & No & Mean $(\mathrm{m} / \mathrm{s})$ & $S D$ & \\
\hline $\begin{array}{l}\text { Median sensory: } \\
\mathrm{N}_{20} \\
\mathbf{P}_{25} \\
\text { Post tibial: }\end{array}$ & $\begin{array}{l}46 \\
46\end{array}$ & $\begin{array}{l}20 \cdot 0 \\
23 \cdot 8\end{array}$ & $\begin{array}{l}1 \cdot 0 \\
2 \cdot 2\end{array}$ & $\begin{array}{l}25 \\
25\end{array}$ & $\begin{array}{l}18 \cdot 6 \\
23 \cdot 7\end{array}$ & $\begin{array}{l}1 \cdot 2 \\
2 \cdot 27\end{array}$ & $<0.0001$ \\
\hline $\mathrm{P}_{40}^{35}$ & $\begin{array}{l}40 \\
40\end{array}$ & $\begin{array}{l}38 \cdot 9 \\
47 \cdot 5\end{array}$ & $\begin{array}{l}2 \cdot 1 \\
2 \cdot 8\end{array}$ & $\begin{array}{l}25 \\
25\end{array}$ & $\begin{array}{l}37 \cdot 4 \\
47 \cdot 5 \\
\end{array}$ & $\begin{array}{l}1 \cdot 4 \\
2 \cdot 5 \\
\end{array}$ & $<0.001$ \\
\hline
\end{tabular}


sufficiently sensitive to detect early abnormalities of brain dysfunction.

The neurophysiological studies on the motor nerves showed that both conduction velocities and distal latency in the median and posterior tibial nerves were significantly prolonged or delayed in the workers exposed to lead by comparison with the control group (table 2). This observation supports other evidence ${ }^{3-5}$ of the presence of abnormalities in nerve conduction studies in the absence of evidence of clinical lead poisoning in workers exposed to lead. In the present study the distal latency was used as a measure to detect early changes and proved to be a sensitive indicator. Since exposure to lead is known to cause axonal degeneration in addition to segmental demyelination, neurophysiological measurements on the distal segments of the peripheral nerves are likely to show the earliest changes in lead neuropathy, and this makes the measurement of the distal latency a useful test with which to detect early neurological abnormalities in lead workers.

The studies on the conduction, velocities in the sensory nerves (the median and sural) showed no statistically significant difference between the two groups (table 2).

Araki and Homma made similar observations in that whereas the motor nerves and motor component of mixed peripheral nerves showed evidence of subclinical damage, the sensory nerves and the sensory component of mixed peripheral nerves were apparently undamaged. ${ }^{10}$ This probably reflects a need for a modified technique to demonstrate damage in sensory nerves. The technique used by Seppalainen $^{2}$ to study conduction velocities in slow fibres may be a more sensitive indicator of early neurophysiological changes induced by lead. Other studies $^{3-5}$ have shown no consistency as to the peripheral nerve most likely to show changes. With the exception of Ashby, ${ }^{4}$ other authors have observed slowing in the maximum motor conduction velocities of the median nerve but only Hernberg has also observed a delay in the distal latencys; in the present study distal latency was prolonged in both the median and posterior tibial nerves (table 2). Possibly the lack of consistency in the published results is because lead does not selectively damage the peripheral nerves but affects them in a random manner.

None of the previous studies has measured SSEP but in the present study it was observed that these values for both median (sensory) $\mathbf{N}_{20}$ value and posterior tibial nerves $\mathbf{P}_{35}$ value were significantly prolonged in the workers exposed to lead (table 3). This finding is of particular importance in view of the fact that no demonstrable differences were observed between the conduction velocities and distal latency of the median (sensory) nerve of the two groups (table 2). It is possible, therefore, that the SSEP measurements may be a more sensitive indicator of sensory nerve damage as they assess the whole sensory neural axis and not merely a peripheral segment. In both the median (sensory) and posteror tibial nerves the second wave components, $P_{25}$ and $N_{40}$ respectively, unlike their relevant first wave values $\left(N_{20}\right.$ and $\left.P_{35}\right)$, were not significantly different from normal. A possible explanation for this may be that these two measurements are made from a bifid wave form and hence there is more likelihood of a variability in measurement; the results may not be accurate enough to reflect early departure from normal.

"A chief concern of much recent research is that the nervous system may still be at serious risk at levels of lead exposure previously considered safe $3.86 \mu \mathrm{mol} / \mathrm{l}$ (about $80 \mu \mathrm{g} / 100 \mathrm{ml}$ blood)." Many countries may still consider this to be a safe value though others would prefer a lower limit. Recently a directive adopted by the Council of Ministers of the European Communities has set a blood lead limit for lead workers of $3.38 \mu \mathrm{mol} / 1(70 \mu \mathrm{g} / 100 \mathrm{ml})^{12}$ while allowing member countries to introduce more stringent protective measures in their national legislation. Furthermore the directive suggests thag studies should be undertaken to determine whethe blood concentration of $1.93 \mu \mathrm{mol} / 1$ (40 $\mu \mathrm{g} / 100 \mathrm{mF}$ should not be the objective for all workers; this is the value suggested by the World Health Organisation $^{12}$ based on the health effects of lead on the haemopoietic and peripheral nervous system. The observations of the present study confirms the need for reappraisal of what is to be considered a safe blood lead concentration for the purposes of monitoring men and women at work.

We are particularly grateful to Professor C Y Tye and Miss Lynette Lim for the generous help in the statistical analysis of the data. Mr Charles Teo is thanked for his help with the neurophysiological measurements. Finally, we thank Miss P C Lim for her efficient and careful typing. The research project was undertaken on a grant from the National University of Singapore (RP 76/82) and thanks are recorded for their financial support.

\section{References}

' Catton MJ, Harrison MJG, Fullerton PM, Kazantzis G. Subclinical neuropathy in lead workers. Br Med J 1970;ii:80-2.

${ }^{2}$ Seppalainen AM, Hernberg S. Sensitive technique for detecting subclinical lead neuropathy. Br J Ind Med 19.72;29:443-9.

${ }^{3}$ Seppalainen AM, Tola S, Hernberg S, Kock B. Subclinical neuropathy at "safe" levels of lead exposure. Arch Environ Health 1975;30:180-3. 
${ }^{4}$ Ashby JAS. A neurological and biochemical study of early lead poisoning. Br J Ind Med 1980;37:133-40.

${ }^{5}$ Hernberg S, Seppalainen AM, Mantere P. A prospective study on early neurotoxic effects of lead. 3rd conference on epidemiology in occupational health, Singapore, 1983. Ann Acad Med Singapore (in press).

- Illis R, Fischbein A, Diamond S, Anderson HA, Selikoff IJ. Lead effects among secondary lead smelter workers with blood lead levels below $80 \mu \mathrm{g} / 100 \mathrm{ml}$. Arch Environ Health 1977;32: 256-65.

' Tong HI, Wong PK. Nerve conduction studies in normal Singapore subjects. Ann Acad Med Singapore 1977;6:251-7.

${ }^{8}$ Devathason G, Puvanendran K, Teo WL, Battacharya S, Wong PK. Visual, brain stem and scalp somatosensory evoked potential-normal values. In: Tan Yew OO, ed. Proceedings of the 16th Singapore-Malaysia congress of medicine 1982. Singapore: Academy of Medicine, 1983.

" Phoon WO, Ong CN. Lead exposure patterns and parameters for monitoring lead absorption among workers in Singapore. Ann Acad Med Singapore 1982; 11:593-600.

${ }^{10}$ Araki S, Homma T. Relationships between lead absorption and peripheral nerve conduction velocities in lead workers. Scand J Environ Health 1976;4:225-31.

"Cooper GP, Sigwart CD. Neurophysiological effects of lead in lead toxicity. In: Singhal RL, Thomas SA, eds. Lead toxicity. Baltimore: Urban and Schwazenberg, 1980.

12 World Health Organisation. Recommended health-based limits in occupational exposure to heavy metals. Geneva: WHO, 1980. (Technical report series 647. )

\section{Vancouver style}

All manuscripts submitted to the $\mathrm{Br} J$ Ind Med should conform to the uniform requirements for manuscripts submitted to biomedical journals (known as the Vancouver style).

The $\mathrm{Br} J$ Ind Med, together with many other international biomedical journals, has agreed to accept articles prepared in accordance with the Vancouver style. The style (described in full in $\mathrm{Br}$ Med J, 24 February 1979, p 532) is intended to standardise requirements for authors.

References should be numbered consecutively in the order in which they are first mentioned in the text by Arabic numerals above the line on each occasion the reference is cited (Manson' confirmed other reports ${ }^{2-5} \ldots$..). In future references to papers submitted to the $\mathrm{Br} J$ Ind Med should include: the names of all authors if there are six or less or, if there are more, the first three followed by $e t$ al; the title of journal articles or book chapters; the titles of journals abbreviated according to the style of Index Medicus; and the first and final page numbers of the article or chapter.

Examples of common forms of references are:

'International Steering Committee of Medical Editors. Uniform requirements for manuscripts submitted to biomedical journals. Br Med J 1979; 1:532-5.

${ }^{2}$ Soter NA, Wasserman SI, Austen KF. Cold urticaria: release into the circulation of histamine and eosinophil chemotactic factor of anaphylaxis during cold challenge. $N$ Engl $J$ Med 1976;294:687-90.

${ }^{3}$ Weinstein L, Swartz MN. Pathogenic properties of invading micro-organisms. In: Sodeman WA Jr, Sodeman WA, eds. Pathologic physiology: mechanisms of disease. Philadelphia: W B Saunders, 1974:457-72. 